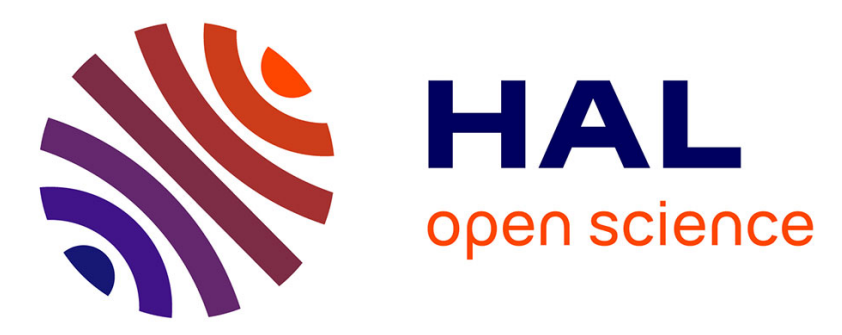

\title{
A Tool for Literary Studies: Intertextual Distance and Tree Classification
}

\author{
Cyril Labbé, Dominique Labbé
}

\section{To cite this version:}

Cyril Labbé, Dominique Labbé. A Tool for Literary Studies: Intertextual Distance and Tree Classification. Literary and Linguistic Computing, 2006, 21 (3), pp.311-326. halshs-00092099

\section{HAL Id: halshs-00092099 \\ https://shs.hal.science/halshs-00092099}

Submitted on 26 May 2008

HAL is a multi-disciplinary open access archive for the deposit and dissemination of scientific research documents, whether they are published or not. The documents may come from teaching and research institutions in France or abroad, or from public or private research centers.
L'archive ouverte pluridisciplinaire HAL, est destinée au dépôt et à la diffusion de documents scientifiques de niveau recherche, publiés ou non, émanant des établissements d'enseignement et de recherche français ou étrangers, des laboratoires publics ou privés. 


\title{
Cyril Labbé
}

Grenoble I University

Cyril.labbe@imag.fr

\section{Dominique Labbé}

Grenoble II University

dominique.labbe@iep.upmf-grenoble.fr

\section{A Tool for Literary Studies \\ Intertextual Distance and Tree Classification}

Draft of the paper published in :

Literary \& Linguistic Computing, 2006, Volume 21, 3, p. 311-326.

\begin{abstract}
How to measure proximities and oppositions in large text corpora? Intertextual distance provides a simple and interesting solution. Its properties make it a good tool for text classification, and especially for tree-analysis which is fully presented and discussed here. In order to measure the quality of this classification, two indices are proposed. The method presented provides an accurate tool for literary studies -as is demonstrated by applying it to two areas of French literature, Racine's tragedies and an authorship attribution experiment.
\end{abstract}

\section{Résumé}

Comment mesurer les proximités et les oppositions dans les grands corpus de texts ? La distance intertextuelle offre une solution simple et intéressante. Ses propriétés en font un excellent outil pour la classification des texts, spécialement la classification arborée qui est présentée et discutée de manière exhaustive. Deux indices sont proposés pour contrôler la qualité de cette classification. Cette méthode présente un outil très utile pour les études littéraires comme le montrent deux applications dans deux domaines : les tragédies de Racine et une expérience d'attribution d'auteur.

lexical statistics ; intertextual distance ; clustering ; tree-analysis ; French literature ; Racine ; authorship attribution 
The degree of proximity between texts and authors is an old question asked in statistics with respect to literary computing. Rather than using a set of "frequent words" or "function words", more or less arbitrarily selected, it is deemed better to take into consideration the entire vocabulary of the texts which are compared. A method for that purpose has already been presented and discussed (Labbé \& Labbé, 2001 ; Merriam, 2002, 2003a \& 2003b). The properties of the resulting intertextual distance make it a good tool for classifications, especially that of "tree-analysis" which is presented and discussed in this paper. Tree analysis is well known in taxonomy or in genetics (a bibliography and a software survey can be found on: http://evolution.genetics.washington.edu; see also: Barthélémy \& Guénoche, 1988). Furthermore, this method already has had a few applications in the field of literary studies (e.g. Juilliard \& Luong, 1997 \& 2001; Matthew \& A1., 2003). It provides an accurate tool for literary studies as seen when applied to two French corpora.

\section{Calculation of intertextual distance}

Given two texts $A$ and $B$. If their lengths (in tokens) are equal, the distance between them can be directly calculated by subtracting the two frequencies of each type from each other and by adding together the sum of the results for all the types occurring in both texts. This sum is a Euclidian distance which gives a quantitative answer to our opening question (for the properties of Euclidian distances applied to texts, see Labbé \& Labbé, 2001; Labbé \& Labbé, 2003). It must be noticed that this distance is derived without any error (presuming the texts contain no spelling mistakes).

If the two texts are not of same length (in tokens), the absolute frequencies can be replaced by relative frequencies. But some questions do arise: does this method neutralise effects of size differences among the texts? Are the properties of the Euclidian distances preserved?

To answer these questions, let us consider:

$-N_{a}$ and $N_{b}$ represent sizes of $A$ and $B$ in tokens with $N_{a}<N_{b}$;

$-F_{i a}$ and $F_{i b}$ represent the absolute frequency of type $i$ in texts $A$ and $B$.

What is the probability of $i$ occurring in a sample of $N_{a}$ tokens drawn out of $B$ ? This expected value — or "mathematical expectancy" $\left(E_{i a}\right)$ - can be easily calculated:

(1) $E_{i a(u)}=F_{i b} * U$ with $U=\frac{N_{a}}{N_{b}}$ 
Considering all the types of $A$ and $B$, the difference between these theoretical frequencies $\left(E_{i a}\right)$ and the observed ones $\left(F_{i a}\right)$ gives the absolute intertextual distance between $A$ and $B$ :

$$
\text { (2) } D_{(A, B)}=\sum_{i \in(A, B)}\left|F_{i a}-E_{i a(u)}\right|
$$

And the relative distance:

$$
\text { (3) } \operatorname{Drel}_{(A, B)}=\frac{\sum_{i \in(A, B)}\left|F_{i a}-E_{i a(u)}\right|}{\sum_{i \in A} F_{i a}+\sum_{i \in B} E_{i a(u)}}
$$

The values of relative distance vary evenly between 0 (the two texts have the same types with the same frequencies) and 1 (the two texts share no words) with neither jump, nor threshold effect around some values. In the following, unless otherwise mentioned, formula (3) is used.

\section{Remarks.}

Of course, the spelling of all words has to be carefully checked and, for French corpora, each token must be tagged in order to reduce the effect of the numerous variable endings of words and the high density of homographs in French (Labbé, 1990)...

The same result could be obtained by placing the $B$ tokens in a vase, shaking them, and drawing from the vase a large number of samples of $N_{a}$ tokens. It must be noticed that, in this experiment:

- when a token is drawn from the vase, it is not replaced since this is the only way to be sure that the number of a type $i$, in a sample of $N_{a}$ tokens extracted from $B$, will be always less than or equal to its frequency in $B\left(E_{i a} \leq F_{i b}\right)$. Thus, this experiment follows a hypergeometric distribution, not a binomial distribution;

- of course, this last method entails a certain margin of error which decreases as the number of samples increases. But this margin of error will be null only when the $\left(N_{b} !-1\right)$ different samples are all considered. Since that is impossible, a safety margin should either be calculated - through hypergeometric variance — or should be estimated (binomial variance). 
Consequently, it is preferable to use formula (3) which gives exactly the same result in a more rapid way and without any margin of error.

In order to facilitate interpretation of the results, the distance values are multiplied by 1,000. Expressed in this way, the result of formula (3) -when applied to two texts A and B (the sizes of which are $\mathrm{N}_{\mathrm{a}}$ and $\mathrm{N}_{\mathrm{b}}$ tokens)- can be defined as: the average number of different tokens which should be counted in all the $\left(N_{a} !-1\right) *\left(N_{b} !-1\right)$ pairs of different samples of 1,000 tokens that can be extracted out of these texts (without replacement).

In formula (3), the denominator is equal to $2 N_{a}$ (neglecting rounding-offs): this calculation gives the two texts the same weightings. This incidentally poses the question as to whether the usual drawbacks generated by size difference between the texts under consideration are neutralised. This method, almost always slightly favours longer texts, because the extraction is performed on all the vocabulary - the size of which is a function of text length — and also as a result of the effect of vocabulary specialisation (see Hubert \& Labbé, 1988). The same problem, of course, occurs when using relative frequencies... In French texts, it appears that this effect can be overlooked in three circumstances: 1) the size of the smallest texts is not too small (in every case: more than 1,000 tokens); 2) the scale proportion between the different texts to be compared is not too large (in every case less than 1:10) and, 3) calculations are performed on texts the spellings of which are normalised, and words of which are lemmatised.

Within these limits, the result has a margin of error equal to less than 5\% (Labbé \& Labbé, 2003). If these limits are taken into account, intertextual "distance" can be considered an Euclidian metric, in the same way that, for example, the everyday distance between two objects can be expressed in meters, or between two cities can be in miles.

Given 2 texts $A$ and $B$, the intertextual distance between them satisfies the following properties:

$-D(A, B)=0$ if and only if $A=B$ (identity);

$-D(A, B)=D(B, A)$ (symmetry);

$-D(A, C) \leq D(A, B)+D(B, C)$ (triangle inequality);

The word "distance" is used only when the measure satisfies these conditions. If not, the words "similarity" and "dissimilarity" refer to measures which are not strictly Euclidian.

Appendix 2 displays the results of this calculation when applied to the eleven tragedies of the well-known $17^{\text {th }}$ century French author Jean Racine (1639-1699: titles and dates of the plays in Appendix 1). 
In the case of distances between Racine's tragedies, it must be remarked that these works are all in alexandrine verse, and they were written within the strict limits of rigorous rules concerning not only prosody but also the "unities" of time, space and action, not to mention constraints of the rules of so-called "decency". Therefore it should be expected that the plays would be very similar to each other (as is the actual case with the tragedies of Corneille, Racine's main rival). But in this corpus, distances between plays are relatively great, especially

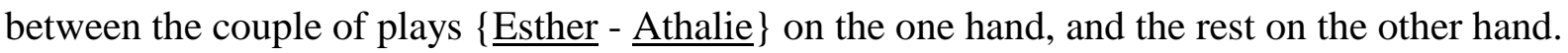
The distance between Bérénice and Esther (346 different types out of one thousand) is far above expected in this kind of corpus (for a single author, plays belonging to the same genre are generally separated by distances between 160 and $250 \%$ o). This large diversity is the main characteristic of Racine's work when compared to all other authors of 17th century French theatre. This example shows one of the numerous opportunities provided by a standardised measurement like the intertextual distance: generalised comparisons become possible between a very large number of authors, texts, and corpora...

As it can be seen in Appendix 2, even with a small corpus like Racine's tragedies, the matrix is not easy to manipulate, and its information is difficult to analyse. Simplification is needed. Firstly some elements are grouped together in order to reduce the matrix size through a "good" classification method. Secondly, the result is graphically represented.

A good method of classification should have the following characteristics. Initially, it should follow an unsupervised method (human interventions entail errors or bias) and without preliminary training (selection of some texts in order to train the algorithm partly induce final results). In addition, it must accurately represent the maximum of the matrix information with the least deformation (this accuracy must be able to be measured). Within these constraints, the tree-classification method seems the most effective adapted tool for textual data processing that currently exists in order to automatically classify data and to represent them graphically. 


\section{Tree-classification of textual distances}

To understand how a classification tree is built and how to interpret it, an example drawn from Racine's work is first presented. Between his eleven tragedies, the largest distance separates Bérénice and Esther. Britannicus is the closest play to Bérénice; Athalie is the closest to Esther. Thus two opposite or contrasting sets can be created and graphically represented by a "tree" (Table 1 and Figure 1).

Table 1. Two sets of contrasting plays in Racine's work (measured in different types out of one thousand)

\begin{tabular}{|l|c|c|c|c|}
\hline & $\underline{\text { Britannicus }}(\mathrm{A})$ & $\underline{\text { Bérénice }}(\mathrm{B})$ & $\underline{\text { Esther }}(\mathrm{C})$ & $\underline{\text { Athalie }}(\mathrm{D})$ \\
\hline$\underline{\text { Britannicus }}$ (A) & 0 & 208 & 314 & 302 \\
\hline$\underline{\text { Bérénice (B) }}$ & 208 & 0 & 346 & 329 \\
\hline$\underline{\text { Esther (C) }}$ & 314 & 346 & 0 & 214 \\
\hline$\underline{\text { Athalie (D) }}$ & 302 & 329 & 214 & 0 \\
\hline
\end{tabular}

Figure 1. Tree representation of Table 1
A. Britann iaus
C. A thalie

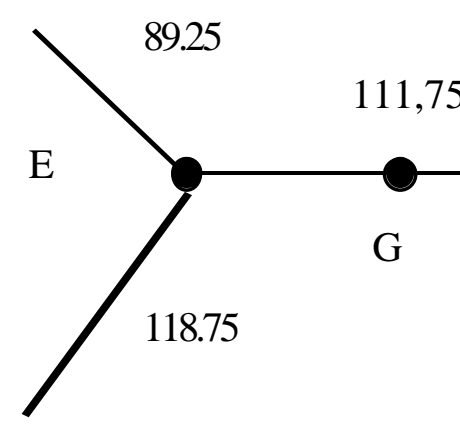

B Bérénice

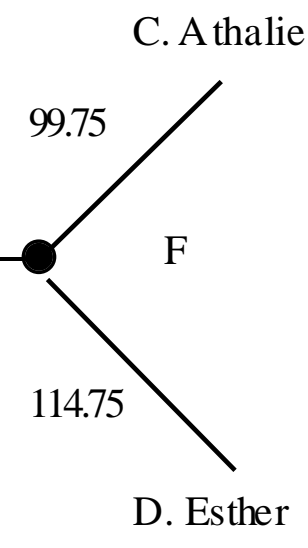

This figure shows a "minimal tree" (it is impossible to draw a tree with less than four points - why this is so will be explained below). $A, B, C$ and $D$ are the "vertices", "end points" or terminal "leaves". $A$ and $B$ are adjacent, so as $C$ and $D$ : they form two sets of "neighbours" and these two contrasting groups are opposite. Points $E$ and $F$ materialise these associations and oppositions: they are nodes of the tree. These two nodes are created by the algorithm 
which establishes their relative positions by calculating lengths of the edges ${ }^{1}$ (or branches) $A E, B E, C F$ and $D F$ which link the leaves to the central trunk $(E F)$. Each point of the tree is linked to another by a path formed by at least one edge. For example, $A E F C$ is the path to follow in order to go from Britannicus to Athalie: the longer the path, the farther away are the two texts. $G$ is the tree root; in Figure 1 it is placed in the middle of the trunk because points $E$ and $F$ are simultaneously created by the algorithm. Usually, the tree root is the last node to be created.

It can also be observed that this tree is "connected": each text (vertex) is linked by at least one edge to all the others. It contains no circuit or loop: there is only one path to link one point to another. This graph is "valued": the path lengths are positive and in fact proportional to the original values in the corresponding cell of the distance matrix (Table 1). For example, it can be seen in Table 1 and Figure 1 that the intertextual distance between Bérénice and Britannicus is equal to the length of the path that links points $A$ and $B(89.25+118.75=208)$.

In Figure 1, neighbouring and opposing relations provide 6 different paths: $A E B, A E F C$, $A E F D, B E F C, B E F D$ and $C F D$. It should be noted that there is no specific direction in which these paths should be taken $(A E B=B E A$, etc. $)$

Among various properties, it can be seen that a minimal tree exists when (and only when) the relation between the four points $(a, b, c, d)$ is:

(4) $D(a, b) \leq \operatorname{Min}\{D(a, c), D(a, d), D(b, c), D(b, d)\}$

It must be noticed that this relation always exists when the four points are located on the same plane. When they are not, a tree is an economical way for representing on a plane multidimensional relations. Sometimes, it entails a "loss" -or compromised approximations- as seen below.

This "four point condition" can be applied to larger populations. Given a series of $n$ texts (with $n>4$ ), $k$ ( 2 or more) out of these $n$ texts can be grouped together, provided that all distances between these $k$ texts, considered by pairs, are less or equal to all the distances separating these $k$ texts from the $n$ - $k$ others in the series (all the possible different pairs must

\footnotetext{
${ }^{1}$ Terminology is sometimes confusing. In geometry, the word "edge" is used for a more than 2-dimension object such as a cube or a tetrahedron. For graphs and trees, "edge" is used for a segment - a straight line bounded on both sides by node(s) or vertex(ices) - even if graphs and trees are almost always 2-dimensional objects...
} 
be taken into consideration). Consequently, these $k$ texts are grouped together and linked through a same node to the other parts of the tree.

Of course, this condition exists in the particular case of two or more equal edges. Such a situation is easy to imagine: in any large city, one can find suburbs located at the four cardinal points nearly the same distance from the centre. The corresponding topological tree will present a cross shape, or a star shape if the number of points is greater than four (and if they are located on more than two axes). For literary studies this result is not inconclusive. The texts concerned can be said to be more or less "equidistant": it provides non-trivial information in many cases.

A number of rules must be kept in mind when analysing a tree. The absolute position of leaves and nodes does not matter. For example, Figure 2 displays some examples from the large number of equivalent trees that can be drawn in order to represent the relationships between these four plays by Racine. The absolute positions in space are not significant. Only proximities and contrasting oppositions and lengths of paths linking leaves and nodes of a tree are considered.

Figure 2. Some example of equivalent trees

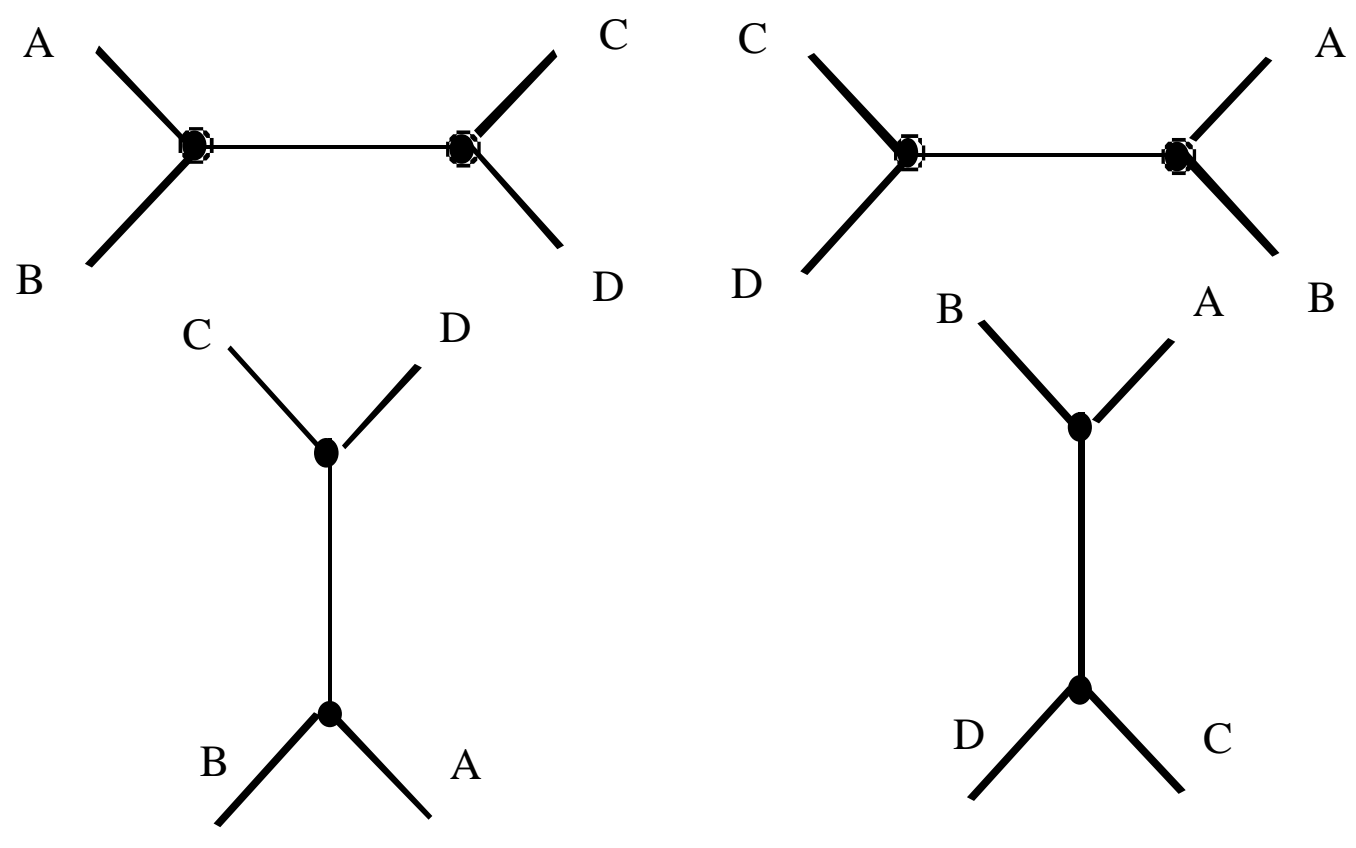

As it can be seen in Table 2, the lengths of these paths (or "tree-distances") can differ slightly from the original values.

Table 2. Distances between four characteristic tragedies of Racine. 


\begin{tabular}{lclcc}
\hline $\begin{array}{l}\text { Paths linking couples of } \\
\text { texts }\end{array}$ & $\begin{array}{c}A \\
\text { Intertextual distance } \\
(\%)\end{array}$ & $\begin{array}{c}B \\
\text { Tree's paths lengths }\end{array}$ & $\begin{array}{c}C \\
|A-B|\end{array}$ & $1-C / A$ \\
& 208 & $89.25+118.75=208$ & 0 & 1.000 \\
$A B$ Bérénice - Britannicus & 214 & $99.75+114.25=214$ & 0 & 1.000 \\
$C D$ Esther - Athalie & 346 & $118.75+111.75+114.25=344.8$ & 1.2 & .997 \\
$A C$ Bérénice - Esther & 329 & $118.75+111.75+99.75=330.3$ & 1.3 & .996 \\
$A D$ Bérénice - Athalie & 314 & $89.25+111.75+114.25=315.3$ & 1.3 & .996 \\
$B C$ Britannicus - Esther & 302 & $89.25+111.75+99.75=300.8$ & 1.2 & .996 \\
$B D$ Britannicus - Athalie & 1713 & & 5 & .997 \\
\hline Sums & & & &
\end{tabular}

If all distances were measured without any adjustment error, the lengths of all these paths should be exactly equal to the corresponding intertextual distances. In reality, they are not. The algorithm used follows Luong's "grouping method" (Luong, 1988): "terminal branches" $(A B, C D)$ are initially calculated, and final fitting is made on the length of the central trunk. When this technique is applied to a large number of very similar texts, it can entail problems that are discussed at the conclusion of this article.

The last column of Table 2 shows that the lengths measured on the tree are very near those of the original data. When texts are of different lengths, the intertextual distance margin of error is less than 5\% above and below the observed values. In this example, these measurement errors explain the slight differences between original measures and lengths in the tree. It can also be observed that the greater the dissimilarity between the two texts, the larger the potential error. Among all Racines' tragedies, the two most divergent pairs are:

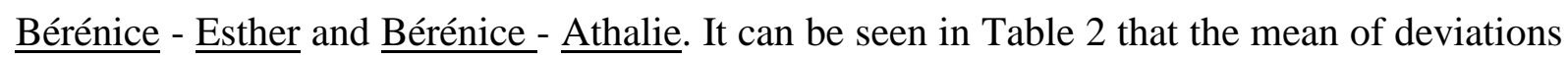
between the original data and their tree-representations is less than $.3 \%$, considerably less than the error margin of calculation. It will be shown below how this information is used to calculate tree quality.

\section{Tree-classification on Racines' tragedies}

The internal diversity of Racine's opus appears clearly with tree classification (Figure 3): the terminal edges are very long and the central trunk seems to be comparatively short (except beyond Iphigénie to the northwest).

This tree has been drawn, step-by-step in an ascending procedure (Luong 1988, Ruhlman, 2003). Appendix 3 gives all the steps, following the grouping order. First, the algorithm performs a search on the two or more nearest texts which are opposed in contrast to all the 
others, in this case, Esther and Athalie. Since the pairs chosen satisfy the "four point conditions", they are grouped together and linked to the rest of the plays through a node $\left(\mathrm{n}^{\circ} 12\right)$. The distance matrix (Appendix 2) is "compressed": the two lines and rows (for Athalie and Esther), are replaced by just one, corresponding to the node $\mathrm{n}^{\circ} 12$; the original distances are replaced by the mean distances between this node and each other text. Then the algorithm groups two or more other texts or nodes, once again compresses the matrix, and so on until less than 4 texts or nodes remain to be grouped. Appendix 3 shows the various steps and the paths opened on the tree by each node.

Figure 3. Tree classification of Racine's tragedies

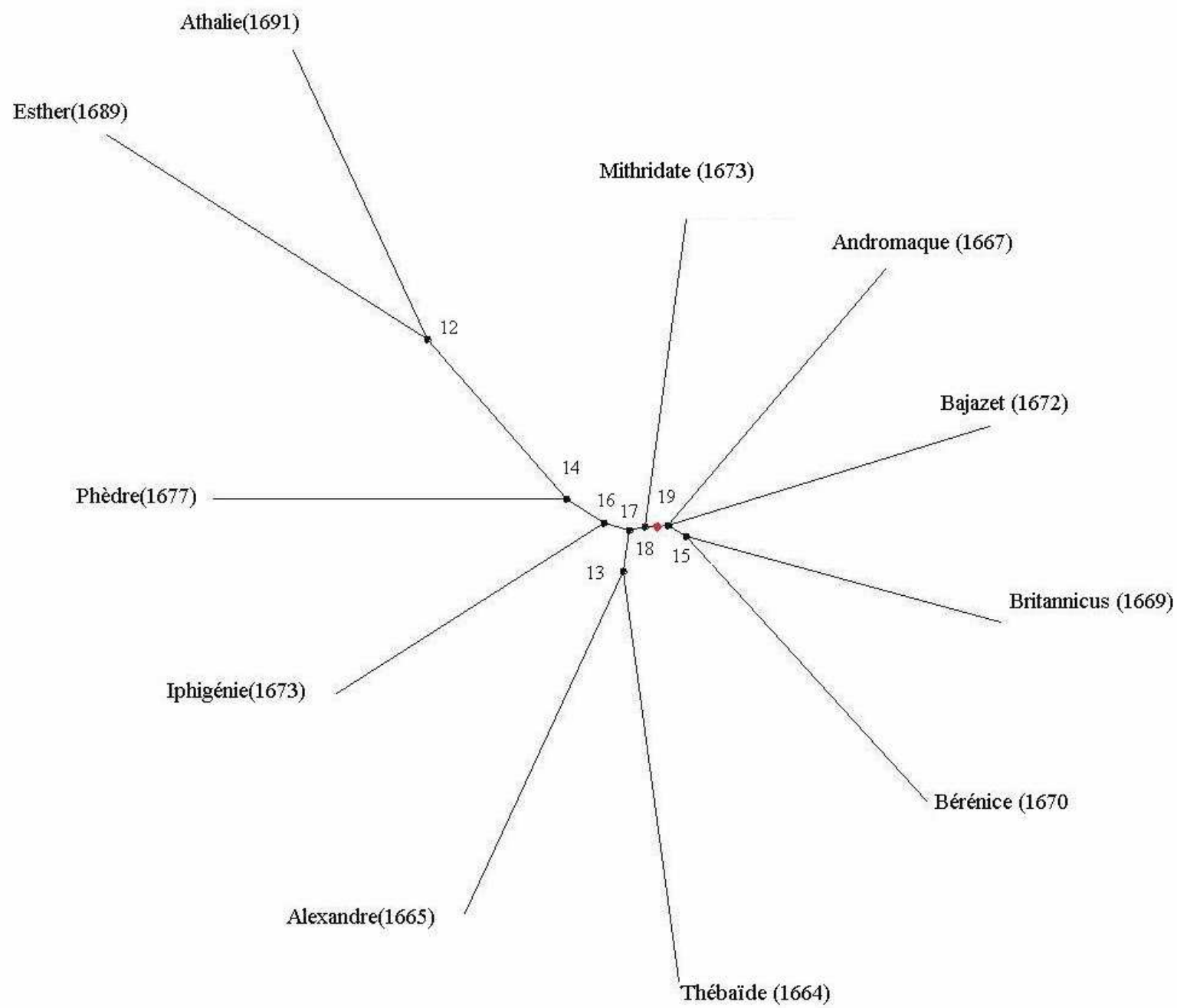

Many corpora, characterised by the same genre, author and chronology, present a characteristic "cross shape" like Figure 3. This phenomenon can be explained by the fact that, 
for between seven out of eleven texts, distances are very much alike, with values between 195 and $250 \%$. In such cases, a simple procedure exists to highlight the marginal fluctuation of a standard chart. The $Y$-Axis is cut off just below the lowest value thus forming the new origin of this axis. Similarly, X. Luong in unpublished private correspondence has offered a solution. He proposed to subtract from all distances in the original matrix a value chosen below the minimum one (in this case, 193\%o: Iphigénie-Mithridate). X. Luong explained that "this reduction will not alter the tree topology but it will reduce only all terminal branches and proportionally increase the length of the trunk between the main nodes", thus providing a kind of "zoom effect" in this crucial zone, and softening the cross shape of the tree. Our experiments have verified Luong's intuition, but it appears that this " tree reduction" entails a real loss of quality of the tree. Figure 4 presents the optimum trade-off between these loss and gain.

Figure 4. Tree classification of Racine's tragedies (Original distances reduced by 150\%o)

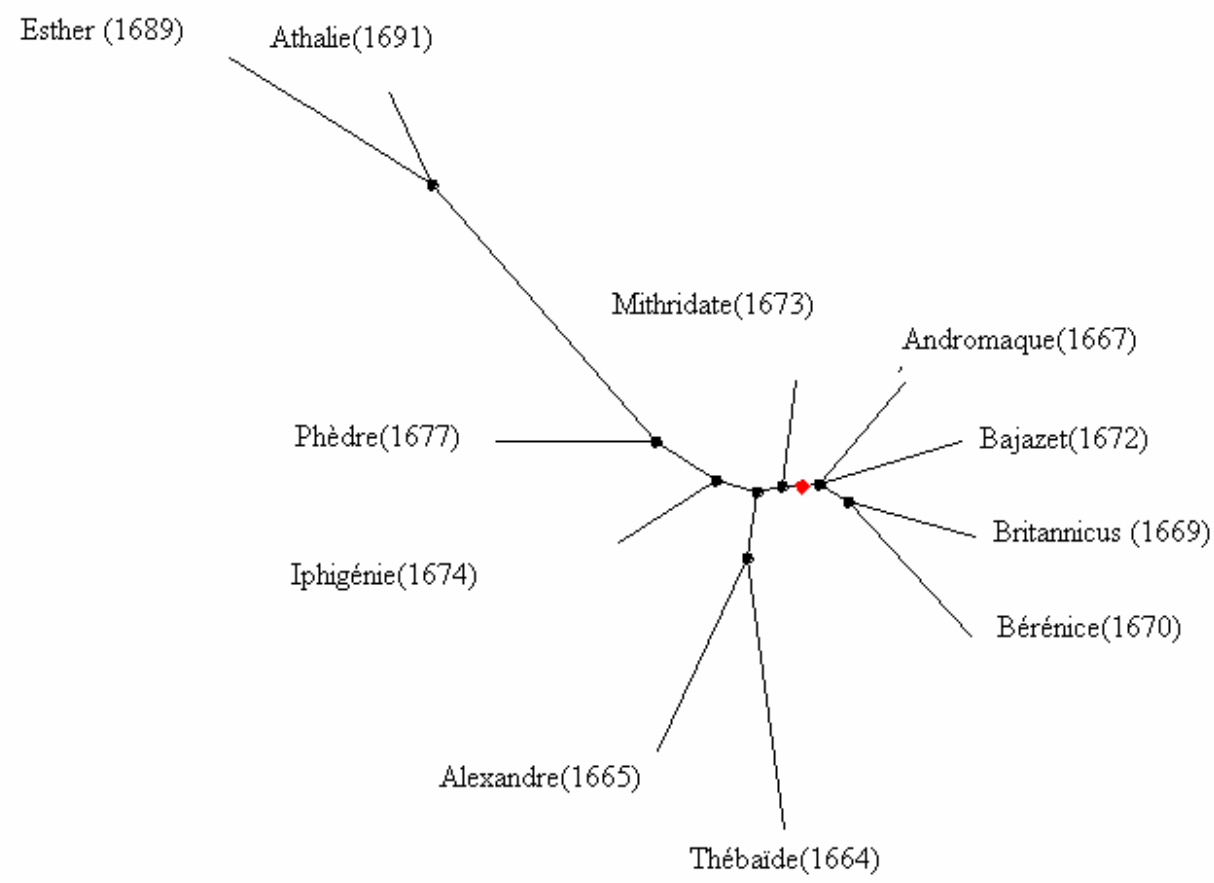

Tree classification separates a few major subsets and clearly isolates the last two plays Athalie (1691) and Esther (1689). This classification seems actually to confirm the conclusions of traditional literary criticism, especially with regard to the main component that appears to be one of chronological order. As a matter of fact, it has been considered that the 
evolution of Racine from Thébaïde (1664) to Phèdre (1677) was quite linear: Racine seemed to have slowly moved away from Corneille's influence. In fact, tree-classification suggests that Racine's evolution was more complex.

Firstly, two "youth plays": Thébaïde and Alexandre (1665) are clearly grouped together and isolated in the lower part of the graph. They share the same themes taken from ancient Greece, and their style is relatively austere, very close to that of Corneille's last plays which are contemporaneous with Thébaïde and $\underline{\text { Alexandre. }}$

At the opposite end of the spectrum, we find the two "sacred tragedies": Esther and Athalie. It is interesting to note that twelve years elapsed between Phèdre (1677) and Esther (1689), and that Racine is thought to have seriously changed his mind about theatre and religion during this twelve year interval. These two "sacred tragedies" were ordered by Mme de Maintenon, the second wife of Louis XIVth, from Racine for the moral edification of the occupants of her orphanage. Racine did not want these plays to be publicly performed and critics consider that they stand apart from his whole work. Figures 3 and 4 clearly confirm this, but they also show that, from the point of view of vocabulary, these plays are the continuation of an evolution begun after Mithridate (1673), many years before.

Four plays, from Andromaque (1667) to Bajazet (1672), form the right-hand cluster in figure 3 and 4. Two of them are "Roman" - Britannicus (1669) and Berenice (1670) - two others are "oriental": Andromaque (1667) Bazajet (1672). The themes remain "Classical" but they are less complicated and the plot is also simplified. Characters are more "complete", more sharply delineated. Correspondingly, richness of vocabulary and stylistic diversity increase.

Mithridate (1673) seems to be a kind of "regression" back in the direction of the first two plays. This play seems to mark a turning-point in Racine's work: he hesitates between a return to his former style and themes, and a move in a new direction. He finally chooses the latter. The last plays spread along the northwest branch of the tree. First, two secular ("profanes") plays, Iphigénie (1673) and Phèdre (1677), in which Racine seems to rediscover Greek mythology, but in a new manner and with a larger vocabulary and stylistic richness than previously, and by emphasising destiny and the will of the Gods.

In other words, Iphigénie and Phèdre open a new way forward. This is perhaps the most interesting conclusion of the experiment. Despite the apparent renunciation of Racine and his 
rallying to the "moral order" which dominates the last part of the 17th century in France, the last four plays can be seen as being linked together like sisters...

\section{Quality measures}

Several questions arise out of these operations. What degree of confidence can be given to the classification and to the chart? Do classification trees always give credible and reliable information with respect to all their component branches? (Spencer \& Al., 2003).

The last column of Table 2 suggests a way to measure the quality of the whole procedure - from the very beginning (text preparation, measurement of intertextual distances) to the determining of the location of the tree root, which terminates the procedure. Given a node $X$ linking two texts A and B, the quality of this grouping is measured by the absolute difference between intertextual distance $\left(D_{(a, b)}\right)$ and the length of the path linking A and B on the tree $\left(P_{(a, b)}\right)$. In order to normalise this index, the absolute difference is divided by the original value $\left(D_{(a, b)}\right)$.

$$
\text { Quality index }\left(X_{(a, b)}\right)=1-\frac{\left|D_{(a, b)}-P_{(a, b)}\right|}{D_{(a, b)}}
$$

This index varies between 1 (no difference between distance and length of path) to 0 (distance is positive and length of path on the tree is non-existent). The index can be interpreted in two ways or both: as an estimation of errors in the measurement of original data and/or as the proportion of information lost in creating the tree classification. In this second interpretation, the index measures the cost to be paid in order to obtain a readable graph with the help of a somewhat imperfect algorithm...

This index has several advantages. It is calculated on each path, on each node - the mean of all paths involved - and on the entire tree (mean of all node quality). So it gives a complete answer to the degree of confidence that one can place on parts or on the entire tree. As can be seen in Appendix 3, for the tree presented in Figure 3, the global quality index is equal to .97 and the quality indices of all the nodes are over .95. It must be taken into account that the calculation of intertextual distances entails a maximum error margin of 5\%. Thus an index equal to, or over $95 \%$, can be considered as an excellent result. Only 6 paths must be pointed 
out due to their quality indexes being under .95, although all above .90 (Table 3 ). In other words, each part of the tree retrieves more than $90 \%$ of the initial information...

Table 3. Problematic paths in figure 3

\begin{tabular}{|c|c|c|}
\hline Node & Path & Quality index \\
\hline \multirow{2}{*}{17} & $\underline{\text { Thébaïde-Esther }}$ & .918 \\
& $\underline{\text { Thébaïde-Athalie }}$ & .901 \\
& Alexandre - $\underline{\text { Athalie }}$ & .939 \\
\hline \multirow{2}{*}{18} & Mithridate-Iphigénie & .935 \\
\hline \multirow{2}{*}{20} & Britannicus-Alexandre & .941 \\
& $\underline{\text { Mithridate-Bérénice }}$ & .941 \\
\hline
\end{tabular}

How can this loss of information be explained? Two explanations can be given to account for the differences between the lengths on the tree and their corresponding distances in the matrix.

First, the original values used to calculate the paths are either too approximate, or they contain errors, or they are not Euclidian metrics (some Euclidian distance properties may not have been respected: often these measures are not exactly symmetrical). In such a case, the original matrix contains "similarity" (or dissimilarity) measures, and it is better to employ the word "distance" only when referring to the lengths of tree paths which best approximate these "similarities".

Second, some degree of "error" or defects may occur when calculating the tree. Of course, this error does not come from topology theory but from imperfections in procedures and algorithms. On the one hand, original dissimilarities are integers, edges are fractional numbers and, because of roundings, their sums never lead exactly to the same results. The differences between columns A and B in Table 2 or in Appendix 3 can partly be explained by this... In Figure 3, the central trunk length is the mean between four paths $(A C, A D, B C, B D)$ less the four terminal branches $(A E B, C F D)$. On the other hand, when the algorithm classifies a large number of texts, it does not calculate all the paths at the same time. Thus a large amount of computational error rests on some short edges (and the central trunk) which are calculated during the last steps. Table 3 shows it occurring in the two following cases: 
— long paths, linking two peripheral texts, which pass through several common edges and a relatively short medial trunk (the final fit is done on this part of the tree). For example, Thébaide-Esther and Alexandre-Athalie.

- paths between centrally located texts directly linked to the medial trunk as is the case with Iphigénie-Mithridate...

Here the cross-shape tree is the major factor. When these "problematic" paths are opened, almost all their lengths are predetermined by previous steps in the procedure (Appendix 3) without possible recalculation (as explained in the conclusion below, this is the major improvement that needs to be made with this algorithm).

A great number of experiments leads to a provisional quality scale:

- .95 and above: excellent (because the index value falls within the margin of error of the original calculation);

- 85-.95: reliable for the whole tree but particular attention must be given to the "critical" edges.

- .75-.85: second-rate: the whole tree must be carefully looked at and can be accepted under certain conditions. It is necessary to draw the reader's attention to some edges which are not reliable (the scores of which are under .85)...

— under .75: rejection of the tree. If this score applies to a single edge or a single node only, it would be possible to accept the tree, but it is necessary to alert the reader to the weak spot of this part of the graph.

This quality scale must be used with care, and it is necessary to emphasize that tree quality can decrease as the number of classified texts increases. As a matter of fact, when $n$ is large, it occasionally occurs that, for the last steps, the "four points condition" is not satisfied for some of these nodes. Two solutions are possible: stop drawing the tree or, as is usually done, lower the requirements by degrading the four points condition. But this problem usually occurs with very short edges so that the overall quality index does not decrease markedly.

Furthermore, the quality index can be combined with another procedure to estimate the confidence that one can put in an entire tree. X. Luong has proposed the following solution (Luong, 1988 and Ruhlman, 2003). The algorithm starts with the two nearest points (out of a total of $n$ points). If their relations to all other texts fulfils the "four points condition" (see formula 4 above), the maximum number of opposites of this couple is: $(n-2)(n-3) / 2$. This 
case can be generalised. Given a group $X$ of $k$ texts $\left(y_{1}, \ldots, y_{k}\right)$ within a corpus of $n$ texts $(2 \leq k<n-2), X$ has a number of potential opposites equal to $(n-k)(n-k-1) / 2$. It is the maximal possible result or "theoretical score" (Sth). For each potential group of texts, the number of actual opposites gives the "observed score" (Sobs). A "confidence index" is calculated by dividing Sobs by Sth. This index varies between 1 (the texts of $X$ are opposed to all others $n-k$ texts) and 0 . It is calculated during each iteration. For the next steps, this index will obviously have fewer possible values and a single failure of the four point condition entails a huge decrease in the index...

Luong's index raises an interesting question: how far must the four point condition be degraded in order to obtain one single group? Of course, if this index is low, less faith can be put in this part of the tree, even if the quality seems to be acceptable.

In any case, it is necessary to publish trees with clear indications as to the following: are the original distances reduced? What are the main values of the quality index? Which are the paths and/or the nodes that are required to degrade the four point condition, and what is the extent of this degrading?

When large corpora are classified, these questions will be of prime importance. This becomes evident, as seen in the context of an experiment carried out with French literature. 


\section{An experiment with French literature}

At the beginning of 2002, prof. E. Brunet (University of Nice, France) arranged an experiment in order to evaluate our method of authorship attribution (Labbé \& Labbé, 2001). He chose a series of texts which omitted details of authors or titles, and sent them to us. $\mathrm{He}$ asked us the precise question: "which are the texts written by the same author?" In July 2002, a report presenting the results of the experiment was sent to Brunet (Labbé, 2002). Then Brunet revealed the authors' names and titles of the books (see Appendix 4). He chose in fact eleven different authors, two novels within the work of each of these authors and two excerpts (of about 10,000 words length) from each novel. In addition to these 44 texts, he made up six "chimerae", sticking together one page out of each novel. These collages or paste-ups were made deliberately: is the algorithm able to recognise the particular nature of these mongrel texts?

The correct answer to Brunet's question was given in the case of the excerpts drawn from the same books. In addition, this answer was given by combining direct examination of the distance matrix with an automatic clustering performed by cluster analysis. The "success" can be explained by the fact that this traditional classification method was perfectly adapted to data organisation by pairs. However, tree-classification introduces a more sophisticated level of information (Figure 5). 
Figure 5. Tree-classification of the "Brunet corpus" (without reduction).

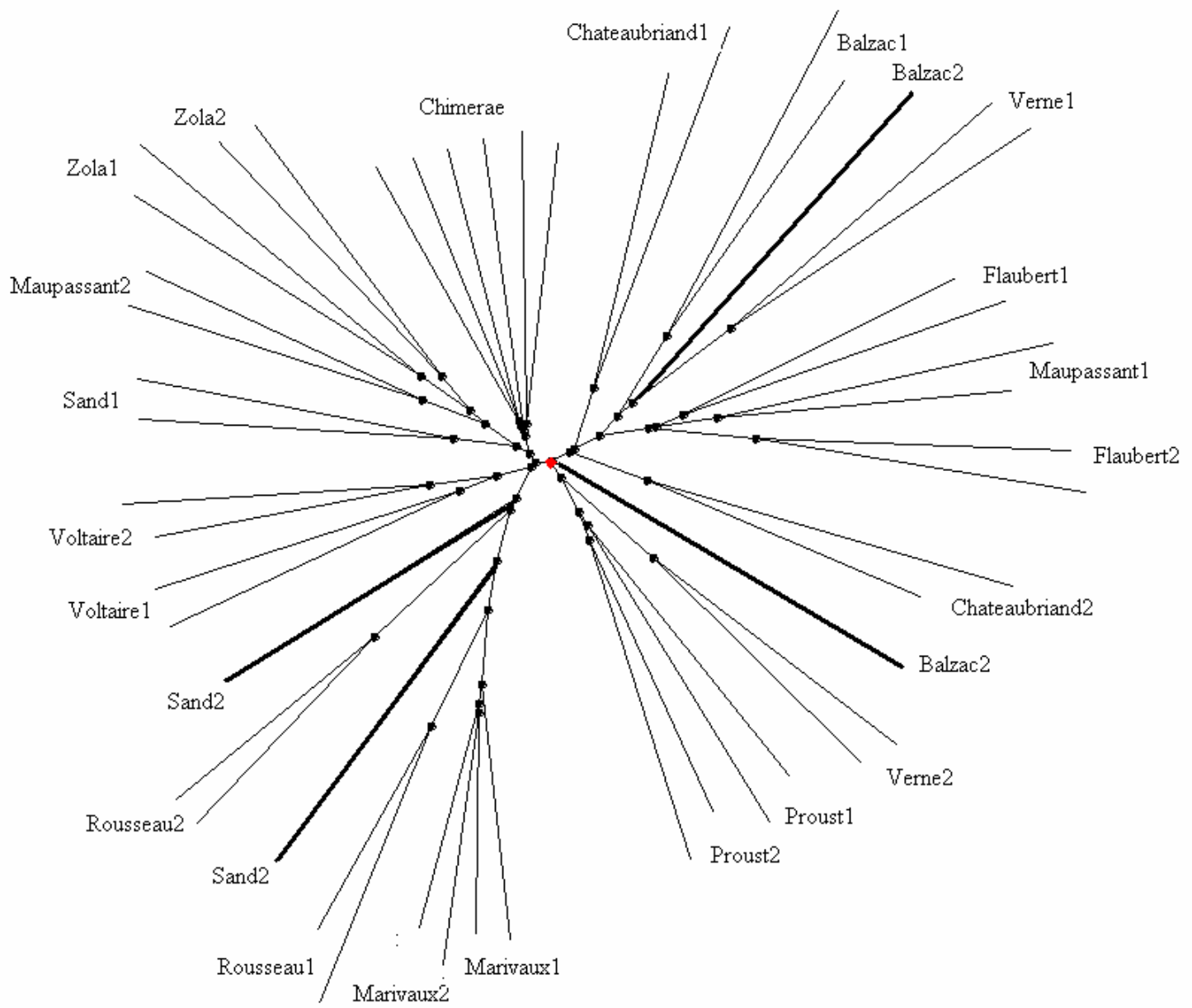

The mean quality index of this tree is .96 and there is no node quality index below .92 . Of the 1225 paths in this graph, all have a quality index above .90 , except for 28 paths the quality indices of which lie within the range ].90 - .83] (these paths involve some of the "strange cases" discussed below). Thus this tree can be considered to be "excellent" but not "perfect". What accounts for this slight information loss?

Once again, the tree presents a cross shape indicating that most of these texts are roughly "equidistant". This is the most complicated situation for the algorithm to handle because it has to work with very slight differences. During the three first iterations, the majority of pairs are joined together without difficulty: the Luong confidence index is always equal to one. But, after this simple first task, the quasi-totality of the tree length is set by the fixed location of the first nodes of the tree as can be clearly seen in Figure 5 (nodes are often very near the centre of the tree). Then a large number of paths need to be recalculated within a very small margin (central trunk and some adjacent edges). More than five hundred paths go along this very 
short trunk and its few adjacent edges, and these edges are the last part of the tree to be calculated using the mean of what is left when nearly all the lengths are already fixed. In the present case, the algorithm can no longer satisfy the "four point conditions" for all these remaining calculations. Generally, one or two tree-distances - among the large number of those which link each of these last "pre-groups" to all other nodes - are insufficiently long.

All the "chimerae" created by E. Brunet in order to "fool" the algorithm are correctly grouped at the top of the tree, clustered together and attached to the central trunk very near the root. To appreciate the accuracy of classification of the 44 other texts, two levels should be considered.

Firstly, is the classification able to recognise the pairs of excerpts drawn from the same book? Within these twenty-two pairs, twenty are correctly classified. Which are the two odd ones (marked with bold lines in the tree)?

- The two excerpts drawn out of La Mare au diable by Georges Sand (1846) are located very close together in the same cluster (South-West) but they are clustered with the two excerpts from l'Emile by Jean-Jacques Rousseau (1762). These books treat the same theme, but they are separated by an interval of nearly a century! This is not entirely surprising because it is common knowledge that at the end of her life, Georges Sand adopted a "Classical" style and used "Neo-classical" themes about rural life.

- The second anomaly comes from Le cousin Pons (Balzac, 1847). The first excerpt is correctly associated with Les Chouans (1841) by the same author. The second excerpt is not really classified: it is attached to the tree root at the end of the classification. In other words, this text seems to be a kind of "stranger". In fact, it contains a large number of peculiar words made up by Balzac in order to "reproduce" the speech of someone speaking French with a German accent.

Secondly, are different books by a same author correctly classified?

Among the eleven authors, only six have all their writings grouped together without ambiguity (Marivaux, Rousseau, Voltaire, Proust, Flaubert, Zola). This result is not surprising. E. Brunet selected a number of difficult cases. For example, for some authors he chose very different works: Chateaubriand 1 (Atala, 1801) is a novel and Chateaubriand 2 is a biography (La vie de Rancé, 1844); nevertheless, they are linked with the same node (through the central trunk). As often as possible, he also selected texts separated by a large interval of time, or known to be very different in style or content. During his lifetime, an author can considerably change his themes and his style, which together enlarge the intertextual distances 
within his work. This corpus gives at least three fascinating examples of this phenomenon: G. Sand, J. Vernes and G. de Maupassant.

For the two first authors, it can be seen that a long period of time elapsed between the two books. For example, G. Sand, who was very "Romantic" at the beginning of her work was very "Neo-classical" at the end of it. G. de Maupassant is also an interesting case. His first novel (Une vie, 1883) is known to be a kind of remake of Madame Bovary (Flaubert, 1857), and it is said that G. Flaubert corrected the manuscript. Logically, Une vie is located in the middle of the Flaubert's cluster and very near Madame Bovary. Six years (and three novels) later, Maupassant seemed to be fully emancipated from Flaubert's influence and Pierre et Jean appears to be very near to E. Zola (at the opposite side of the tree...). Thus, it may be deemed that the tree classification in this case was not really erroneous and that, on the contrary, it provides an accurate tool for literary history.

Consequently, as far as strictly authorship attribution is concerned, it is clear that the texts to be compared must belong to the same genre; they also must be contemporaneous and without too many "anomalies" (like the funny French of the German friend of Balzac's Cousin Pons). At least, it must be kept in mind that tree-classification does not provide "proof" and that these graphs must be carefully analysed. A tree can only suggest certain affinities or, on the other hand, some impossibilities. Furthermore, intertextual distances provide numerically standardised answers and not only "visual" ones. It must be emphasized that, for this "Brunet" corpus, intertextual distances alone allowed us correctly to identify more than three fourths of the couples within the many thousand possibilities, and gave the most probable solutions for all the others without error.

\section{Conclusion :}

A more sophisticated algorithm is planned which should construct trees in two main steps. Firstly, following the procedure presented in this article, all points and nodes should be situated, and edges should be allotted provisional lengths. Then all these edges should be recalculated in order to distribute the required adjustments along the whole length of the different paths, and not merely on a few sections of them as is presently done. This solution is necessary to adapt tree-classification fully to large corpora of several hundred texts.

Fundamentally, tree quality relies on the manner by which proximity between texts is measured. Of course, texts must have been carefully checked and word spellings strictly 
standardised, because it is useless to attempt accurately to measure phenomena whose observations are made inaccurately. Secondly, these measures of proximity must be as near as possible to the usual Euclidian distance characteristics. Within certain limits, it is indeed mostly the case with intertextual distance. Thus combining intertextual distance with treeclassification provides an accurate tool for researchers to help them process an ever-growing body of electronic texts available for literary studies. This procedure will soon be adapted to English texts and corpora.

Note:

— software are on line (http://www.upmf-grenoble.fr/cerat/Recherche/PagesPerso/Labbe)

- the work of Racine and the Brunet corpus are freely available on line (http://ota.ahds.ac.uk/2466)

\section{Acknowledgments}

The authors are grateful to Mathieu Ruhlman (Polytech' Grenoble) who wrote the software and carried out the experiments, presented in this paper, under our supervision during the summer of 2003; to Xuan Luong (University of Nice) who put at our disposal his own software and patiently answered all our questions; to Etienne Brunet who provided the texts for the blind test. We also thank Edward Arnold (University of Dublin) for his accurate reading of our first translation and Thomas Merriam for his helpful comments and advice about intertextual distance and for his final edition of this text.

\section{Bibliography}

Above all, tree-classification is used in genetics and toxonomy. A bibliographical and a software survey can be found on: http://evolution.genetics.washington.edu

Barthélémy Jean-Pierre and Guénoche Alain (1988). Les arbres et les représentations de proximité. Paris. Dunod (english translation: Trees and Proximity Representations, New York, Wiley, 1991).

Juilliard Michel and Luong Xuan (1997), "Words in the Hood", Literary and Linguistic computing, 12-2, p. 71-78.

Juilliard Michel and Luong Xuan (2001), "On consensus between Tree-Representation of Linguistic Data", Literary and Linguistic computing, 16-1, p. 59-76. 
Hubert Pierre and Labbé Dominique. "A model of Vocabulary Partition". Literary and Linguistic Computing. 3-4. 1988. p. 223-225.

Labbé Cyril and Labbé Dominique (2001). "Inter-Textual Distance and Authorship Attribution Corneille and Molière". Journal of Quantitative Linguistics. 8-3. December 2001. p 213-231.

Labbé Cyril and Labbé Dominique (2003). "La distance intertextuelle". Corpus. 2-2003. p 95118.

Labbé Dominique (1990). Normes de saisie et de dépouillement des textes politiques. Grenoble. Cahier du CERAT.

This text is on line: http://www.upmf-grenoble.fr/cerat/Recherche/PagesPerso/Labbe

Labbé Dominique (2002). Qui a écrit quoi?. Grenoble. Cerat.

This text is on line: http://www.upmf-grenoble.fr/cerat/Recherche/PagesPerso/Labbe

Luong Xuan (1988). Méthodes d'analyse arborée. Algorithmes, applications. Thèse pour le doctorat ès sciences. Université de Paris V.

Merriam Thomas (2002). "Intertextual Distances between Shakespeare Plays, with Special Reference to Henry V (verse)". Journal of Quantitative Linguistics. 9-3. December 2002. p 260-273.

Merriam Thomas (2003a). "An Application of Authorship Attribution by Intertextual Distance in English". Corpus. 2. 2003. p 167-182.

Merriam Thomas (2003b). "Intertextual Distances, Three Authors". Literary and Linguistic Computing, 18-4, 379-388.

Ruhlman Mathieu (2003), Analyse arborée. Représentation par la méthode des groupements. Grenoble, Polytech' - CERAT, août 2003.

This text is on line: http://www.upmf-grenoble.fr/cerat/Recherche/PagesPerso/Labbe

Spencer Matthew, Bordalejo Barbara, Robinson Peter, Howe Christopher (2003), "How Reliable is a Stemma ? An Analysis of Chaucer's Miller's Tale", Literary and Linguistic computing, 18-4, 2003, p 407-422. 
Appendix I Racine's work

\begin{tabular}{|clcccc|}
\hline $\mathrm{N}^{\circ}$ & \multicolumn{1}{c}{ Title } & Genre & Date & Length (tokens) & Types \\
\hline 1 & La Thébaïde & Tragedy & 1664 & 13,813 & 1,313 \\
2 & Alexandre & Tragedy & 1665 & 13,864 & 1,372 \\
3 & Andromaque & Tragedy & 1667 & 15,076 & 1,392 \\
4 & Les Plaideurs & Comedy & 1668 & 8,041 & 1,312 \\
5 & Britannicus & Tragedy & 1669 & 15,387 & 1,637 \\
6 & Bérénice & Tragedy & 1670 & 13,242 & 1,346 \\
7 & Bajazet & Tragedy & 1672 & 15,297 & 1,507 \\
8 & Mithridate & Tragedy & 1673 & 15,091 & 1,550 \\
9 & Iphigénie & Tragedy & 1674 & 15,782 & 1,604 \\
10 & Phèdre & Tragedy & 1677 & 14,394 & 1,775 \\
11 & Esther & Tragedy & 1689 & 11,147 & 1,656 \\
12 & Athalie & Tragedy & 1691 & 15,492 & 1,656 \\
\hline & Entire work & & & 166,626 & 4,322 \\
\hline
\end{tabular}


Appendix 2. Intertextual distances between tragedies by Racine

\begin{tabular}{|c|c|c|c|c|c|c|c|c|c|c|c|}
\hline & Thébaïde & Alexandre & Andromaque & Britannicus & Bérénice & Bazajet & Mithridate & Iphigénie & Phèdre & Esther & Athalie \\
\hline Thébaïde & 0 & 242 & 245 & 260 & 276 & 258 & 242 & 254 & 275 & 317 & 295 \\
\hline Alexandre & 242 & 0 & 231 & 233 & 260 & 251 & 238 & 241 & 266 & 315 & 295 \\
\hline Andromaque & 245 & 231 & 0 & 214 & 227 & 202 & 208 & 223 & 245 & 331 & 306 \\
\hline Britannicus & 260 & 233 & 214 & 0 & 208 & 206 & 218 & 222 & 246 & 314 & 302 \\
\hline Bérénice & 276 & 260 & 227 & 208 & 0 & 220 & 206 & 226 & 250 & 346 & 329 \\
\hline Bazajet & 258 & 251 & 202 & 206 & 220 & 0 & 204 & 230 & 244 & 325 & 304 \\
\hline Mithridate & 242 & 238 & 208 & 218 & 206 & 204 & 0 & 193 & 223 & 313 \\
\hline Iphigénie & 254 & 241 & 223 & 222 & 226 & 230 & 193 & 0 & 216 & 293 \\
\hline Phèdre & 275 & 266 & 245 & 246 & 250 & 244 & 224 & 216 & 0 & 280 \\
\hline Esther & 317 & 315 & 331 & 314 & 346 & 325 & 313 & 293 & 286 & 275 \\
\hline Athalie & 295 & 295 & 306 & 302 & 329 & 304 & 288 & 280 & 275 & 214 \\
\hline
\end{tabular}


Appendix 3. Calculation steps and quality indices for tree-classification of Racine's tragedies

\begin{tabular}{|c|c|c|c|c|c|}
\hline Node & Paths & Texts distances* & Tree distances* & Path's Quality & Node's Quality \\
\hline 12 & Esther - Athalie & 214.5 & 214.5 & 1.00 & 1.00 \\
\hline 13 & Thébaïde - Alexandre & 242.2 & 242.2 & 1.00 & 1.00 \\
\hline 14 & $\begin{array}{l}\text { Phèdre - Esther } \\
\text { Phèdre - Athalie }\end{array}$ & $\begin{array}{l}285.7 \\
275.2 \\
\end{array}$ & $\begin{array}{l}289.8 \\
271.1 \\
\end{array}$ & $\begin{array}{l}.99 \\
.99 \\
\end{array}$ & .99 \\
\hline 15 & Britannicus - Bérénice & 209.4 & 209.4 & 1.00 & 1.00 \\
\hline 16 & $\begin{array}{l}\text { Iphigénie - Phèdre } \\
\text { Iphigénie - Esther } \\
\text { Iphigénie - Athalie }\end{array}$ & $\begin{array}{l}215.5 \\
293.1 \\
280.4 \\
\end{array}$ & $\begin{array}{l}219.1 \\
292.4 \\
273.8 \\
\end{array}$ & $\begin{array}{c}.98 \\
1.00 \\
.98 \\
\end{array}$ & .99 \\
\hline 17 & $\begin{array}{l}\text { Thébaïde - Iphigénie } \\
\text { Thébaïde - Phèdre } \\
\text { Thébaïde - Esther } \\
\text { Thébaïde - Athalie } \\
\text { Alexandre - Iphigénie } \\
\text { Alexandre - Phèdre } \\
\text { Alexandre - Esther } \\
\text { Alexandre - Athalie }\end{array}$ & $\begin{array}{l}253.9 \\
275.3 \\
317.3 \\
295.1 \\
240.9 \\
265.5 \\
315.4 \\
294.9 \\
\end{array}$ & $\begin{array}{l}245.1 \\
269.9 \\
343.2 \\
324.6 \\
233.5 \\
258.4 \\
331.7 \\
313.0 \\
\end{array}$ & $\begin{array}{l}.97 \\
.98 \\
.92 \\
.90 \\
.97 \\
.97 \\
.95 \\
.94 \\
\end{array}$ & .95 \\
\hline 18 & $\begin{array}{l}\text { Mithridate - Thebaide } \\
\text { Mithridate - Alexandre } \\
\text { Mithridate - Iphigénie } \\
\text { Mithridate - Phèdre } \\
\text { Mithridate - Esther } \\
\text { Mithridate - Athalie }\end{array}$ & $\begin{array}{l}242.1 \\
237.8 \\
192.5 \\
223.4 \\
313.0 \\
287.5\end{array}$ & $\begin{array}{l}239.4 \\
227.9 \\
205.0 \\
229.9 \\
303.2 \\
284.5\end{array}$ & $\begin{array}{l}.99 \\
.96 \\
.93 \\
.97 \\
.97 \\
.99\end{array}$ & .97 \\
\hline 19 & $\begin{array}{l}\text { Andromaque - Bazajet } \\
\text { Andromaque - Britannicus } \\
\text { Andromaque - Bérénice } \\
\text { Bazajet - Britannicus } \\
\text { Bazajet - Bérénice } \\
\end{array}$ & $\begin{array}{l}202.2 \\
213.5 \\
226.6 \\
205.5 \\
219.5 \\
\end{array}$ & $\begin{array}{l}206.2 \\
209.5 \\
219.1 \\
209.4 \\
219.0 \\
\end{array}$ & $\begin{array}{l}.98 \\
.98 \\
.97 \\
.98 \\
1.00 \\
\end{array}$ & .98 \\
\hline 20 & $\begin{array}{l}\text { Andromaque - Thébaïde } \\
\text { Andromaque - Alexandre } \\
\text { Andromaque - Iphigénie } \\
\text { Andromaque - Phèdre } \\
\text { Andromaque - Esther } \\
\text { Andromaque - Athalie } \\
\text { Bazajet - Thébaïde } \\
\text { Bazajet - Alexandre } \\
\text { Bazajet - Iphigénie } \\
\text { Bazajet - Phèdre } \\
\text { Bazajet - Esther } \\
\text { Bazajet - Athalie } \\
\text { Britannicus - Thébaïde } \\
\text { Britannicus - Alexandre } \\
\text { Bérénice - Thébaïde } \\
\text { Bérénice - Alexandre } \\
\text { Britannicus - Iphigénie } \\
\text { Britannicus - Phèdre } \\
\text { Britannicus - Esther } \\
\text { Britannicus - Athalie } \\
\text { Bérénice - Iphigénie } \\
\text { Bérénice - Phèdre } \\
\text { Bérénice - Esther } \\
\text { Bérénice - Athalie } \\
\text { Mithridate - Andromaque } \\
\text { Mithridate - Bazajet } \\
\text { Mithridate - Britannicus } \\
\text { Mithridate - Bérénice }\end{array}$ & $\begin{array}{l}244.9 \\
231.0 \\
222.5 \\
244.5 \\
331.0 \\
305.9 \\
257.5 \\
250.7 \\
230.3 \\
243.8 \\
324.6 \\
303.8 \\
260.3 \\
232.9 \\
276.0 \\
260.0 \\
221.6 \\
246.3 \\
314.2 \\
301.5 \\
225.9 \\
250.0 \\
346.2 \\
328.5 \\
208.4 \\
203.8 \\
217.6 \\
206.1\end{array}$ & $\begin{array}{l}255.0 \\
243.5 \\
220.6 \\
245.4 \\
318.7 \\
300.1 \\
254.9 \\
243.4 \\
220.5 \\
245.3 \\
318.6 \\
300.0 \\
258.2 \\
246.6 \\
267.8 \\
256.3 \\
223.8 \\
248.6 \\
321.9 \\
303.2 \\
233.4 \\
258.2 \\
331.5 \\
312.9 \\
205.4 \\
205.3 \\
208.5 \\
218.2\end{array}$ & $\begin{array}{c}.96 \\
.95 \\
.99 \\
1.00 \\
.96 \\
.98 \\
.99 \\
.97 \\
.96 \\
.99 \\
.98 \\
.99 \\
.99 \\
.94 \\
.97 \\
.99 \\
.99 \\
.99 \\
.98 \\
.99 \\
.97 \\
.97 \\
.96 \\
.95 \\
.99 \\
.99 \\
.96 \\
.94\end{array}$ & .97 \\
\hline
\end{tabular}

$*$ number of different type words out of one thousand words 
Appendix 4. The Brunet corpus

\begin{tabular}{|c|c|c|}
\hline $\mathrm{N}^{\circ}$ & Author & Titles (date) \\
\hline 1 & Marivaux 1.1 & La vie de Marianne (1731) \\
\hline 2 & Marivaux 2.1 & Le paysan parvenu (1735) \\
\hline 3 & Voltaire 1.1 & Zadig (1747) \\
\hline 4 & Voltaire 2.1 & Candide (1759) \\
\hline 5 & Rousseau 1.1 & La nouvelle Héloïse (1761) \\
\hline 6 & Rousseau 2.1 & L'Emile (1762) \\
\hline 7 & Chateaubriand 1.1 & Atala $(1801)$ \\
\hline 8 & Chateaubriand 2.1 & La vie de Rancé (1844) \\
\hline 9 & Balzac 1.1 & Les Chouans (1841) \\
\hline 10 & Balzac 2.1 & Le cousin Pons (1847) \\
\hline 11 & Sand 1.1 & Indiana (1832) \\
\hline 12 & Sand 2.1 & La mare au diable (1846) \\
\hline 13 & Flaubert 1.1 & Madame Bovary (1857) \\
\hline 14 & Flaubert 2.1 & Bouvard et Pécuchet (1881) \\
\hline 15 & Maupassant 1.1 & Une vie (1883) \\
\hline 16 & Maupassant 2.1 & Pierre et Jean (1888) \\
\hline 17 & Zola 1.1 & Thérèse Raquin (1867) \\
\hline 18 & Zola 2.1 & La bête humaine(1890) \\
\hline 19 & Verne 1.1 & De la terre à la lune (1865) \\
\hline 20 & Verne 2.1 & Les secrets de Wilhelm Storitz (1905) \\
\hline 21 & Proust 1.1 & Du côté de chez Swann (1913) \\
\hline 22 & Proust 2.1 & Le temps retrouvé (1927) \\
\hline 23 & Marivaux 1.2 & La vie de Marianne (1731) \\
\hline 24 & Marivaux 2.2 & Le paysan parvenu (1735) \\
\hline 25 & Voltaire 1.2 & Zadig (1747) \\
\hline 26 & Voltaire 2.2 & Candide (1759) \\
\hline 27 & Rousseau 1.2 & La nouvelle Héloïse (1761) \\
\hline 28 & Rousseau 2.2 & L'Emile (1762) \\
\hline 29 & Chateaubriand 1.2 & Atala $(1801)$ \\
\hline 30 & Chateaubriand 2.2 & La vie de Rancé (1844) \\
\hline 31 & Balzac 1.2 & Les Chouans (1841) \\
\hline 32 & Balzac 2.2 & Le cousin Pons (1847) \\
\hline 33 & Sand 1.2 & Indiana (1832) \\
\hline 34 & Sand 2.2 & La mare au diable (1846) \\
\hline 35 & Flaubert 1.2 & Madame Bovary (1857) \\
\hline 36 & Flaubert 2.2 & Bouvard et Pécuchet (1881) \\
\hline 37 & Maupassant 1.2 & Une vie (1883) \\
\hline 38 & Maupassant 2.2 & Pierre et Jean (1888) \\
\hline 39 & Zola 1.2 & Thérèse Raquin (1867) \\
\hline 40 & Zola 2.2 & La bête humaine(1890) \\
\hline 41 & Verne 1.2 & De la terre à la lune (1865) \\
\hline 42 & Verne 2.2 & Les secrets de Wilhelm Storitz (1905) \\
\hline 43 & Proust 1.2 & Du côté de chez Swann (1913) \\
\hline 44 & Proust 2.2 & Le temps retrouvé (1927) \\
\hline 45 & Brunet's collages : & Pages $n^{\circ} 1$ out of all the texts \\
\hline 46 & & Pages $n^{\circ} 10$ out of all the texts \\
\hline 47 & & Pages $n^{\circ} 20$ out of all the texts \\
\hline 48 & & Pages $n^{\circ} 30$ out of all the texts \\
\hline 49 & & Pages $n^{\circ} 40$ out of all the texts \\
\hline 50 & & Pages $n^{\circ} 50$ out of all the texts \\
\hline
\end{tabular}

